\title{
Microstructure and mechanical properties of A791D magnesium alloy by expendable pattern shell casting with different mechanical vibration amplitudes and pouring temperatures
}

\author{
*Suo Fan', He-bao Wu', Jin-xiu Fang ${ }^{2,3}$ \\ 1. School of Mechanical \& Electrical Engineering, Wuhan Institute of Technology, Wuhan 430073, China \\ 2. School of Metallurgic Engineering, Anhui University of Technology, Ma'anshan 243002, China \\ 3. Maanshan Ruihui Industrial Co., Ltd., Ma'anshan 243002, China
}

\begin{abstract}
To refine the microstructure and improve the mechanical properties of AZ91D alloy by expendable pattern shell casting (EPSC), the mechanical vibration method was applied in the solidification process of the alloy. The effects of amplitude and pouring temperature on microstructure and mechanical properties of AZ91D magnesium alloy were studied. The results indicated that the mechanical vibration remarkably improved the sizes, morphologies and distributions of the primary $\alpha-\mathrm{Mg}$ phase and $\beta-\mathrm{Mg}_{17} \mathrm{Al}_{12}$ phase, and the densification and tensile properties of the AZ91D alloy. With an increase in amplitude, the microstructures were gradually refined, resulting in a continuous increase in mechanical properties of the AZ91D alloy. While, with the increase of pouring temperature, the microstructures were continuously coarsened, leading to an obvious decrease of the mechanical properties. The tensile strength and yield strength of the AZ91D alloy with a vibration amplitude of 1.0 $\mathrm{mm}$ and a pouring temperature of $730{ }^{\circ} \mathrm{C}$ were $60 \%$ and $38 \%$ higher than those of the alloy without vibration, respectively.
\end{abstract}

Key words: AZ91D magnesium alloy; expendable pattern shell casting; mechanical vibration; microstructure; mechanical properties
CLC numbers: TG146.22
Document code: $\mathrm{A}$
Article ID: 1672-6421(2021)01-001-08

\section{Introduction}

There is an increasing demand for complicated magnesium alloy precision castings in the aerospace and automotive industries due to their many advantages, such as low density, high specific strength, excellent castability and electromagnetic shielding capacity ${ }^{[1-3]}$. Expendable pattern shell casting (EPSC) technology that combines the foam pattern preparation of lost foam casting (LFC), the thin shell precision fabrication of investment casting, and the negative pressure pouring technology is considered a novel precision casting process, which is suitable for manufacturing complicated magnesium and aluminum alloys precision castings with a high quality ${ }^{[4]}$. The EPSC process has a number

\section{*Suo Fan}

Male, Ph. D., Lecturer. Research interests: precision casting forming technology of aluminum and magnesium alloys.

E-mail: fan_suo@163.com;

Received: 2020-08-13; Accepted: 2020-09-18 of merits, such as flexible design and low cost of the LFC technology and high precision of the investment casting process. The porosity and slag inclusion defects resulting from the decomposition of the foam pattern during the LFC process can be completely avoided as the foam pattern has been removed before pouring. What is more, the filling ability and feeding capacity of the liquid metal are improved under the vacuum negative pressure.

However, the primary $\alpha-\mathrm{Mg}$ phase of the magnesium alloys processed by the EPSC process exhibits a coarse and inhomogeneous dendritic morphology, and the $\beta-\mathrm{Mg}_{17} \mathrm{Al}_{12}$ phase distributes along the $\alpha-\mathrm{Mg}$ grain boundary with a coarse continuous network structure, leading to poor mechanical properties. As is known, the mechanical vibration is a simple, economic, and effective method to refine microstructure and improve mechanical properties ${ }^{[5-8]}$. Some researchers have systematically studied the effect of mechanical vibration on microstructure and mechanical properties of aluminum alloy by the EPSC process ${ }^{[9,10]}$. However, there are few investigations on the effect of the vibration 
amplitude and pouring temperature on the microstructure and mechanical properties of AZ91D magnesium alloy.

In this work, to improve the microstructure and mechanical properties of the AZ91D alloy, a simple and economic mechanical vibration method was applied in the solidification process of the AZ91D alloy by EPSC process. The aim of this work is to systematically investigate the effects of the amplitude and pouring temperature on the microstructure and mechanical properties of the AZ91D alloy using the EPSC process, to obtain the optimal process parameters.

\section{Experimental procedure}

Foam pattern samples were fabricated by the foaming molding method, and the foam patterns were then coated with the ceramic slurry and refractory to prepare the ceramic shell. The foam pattern together with the shell were placed into an electric furnace to remove the foam pattern material and bake the ceramic shell. The ceramic shell was then placed in a sand flask, and the sand flask was filled with loose sand. A vibration table was then used to compact the loose sand. Finally, a plastic film was laid to cover the surface of the sand flask, waiting for the pouring process.

The commercial AZ91D magnesium alloy ingots were placed inside the stainless steel crucible in an electrical resistance furnace to melt at $750{ }^{\circ} \mathrm{C}$, and the protective gas was a $\mathrm{CO}_{2}$ $0.5 \% \mathrm{SF}_{6}$ mixture. Table 1 lists the chemical compositions of the alloy. Prior to pouring, the slag of the molten metal was skimmed; meanwhile, the vacuum pump and vibration table were started. The AZ91D magnesium melt was poured at different temperatures into the ceramic shell mold cavity. The vibration time was 3 min with different amplitudes. Figure 1 shows a schematic illustration of the experimental apparatus of the EPSC process associated with mechanical vibration.

Table 1: Chemical compositions of AZ91D magnesium alloy (wt.\%)

\begin{tabular}{cccccccc}
$\mathrm{Al}$ & $\mathrm{Zn}$ & $\mathrm{Mn}$ & $\mathrm{Si}$ & $\mathrm{Fe}$ & $\mathrm{Cu}$ & $\mathrm{Ni}$ & $\mathrm{Mg}$ \\
\hline 8.96 & 0.8 & 0.28 & 0.07 & 0.039 & 0.024 & 0.001 & Bal.
\end{tabular}

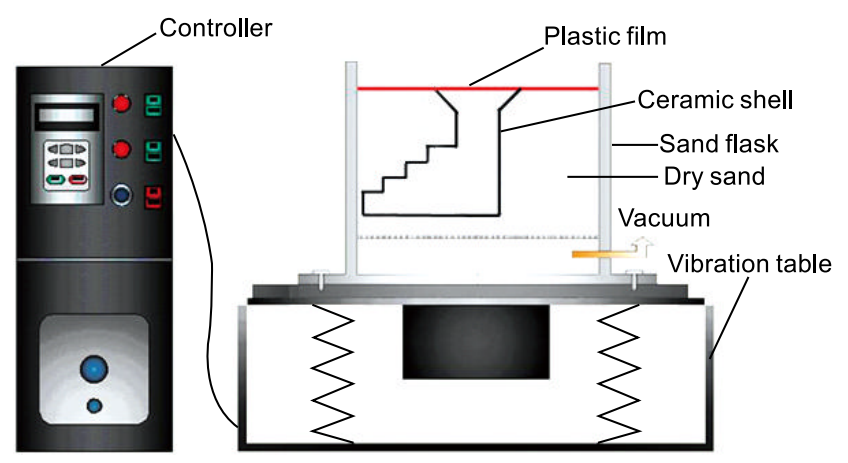

Fig. 1: Schematic illustration of experimental apparatus of EPSC process associated with mechanical vibration
The process parameters including different amplitudes and pouring temperatures are listed in Table 2. The vibration frequency was chosen as $100 \mathrm{~Hz}$ based on Refs. [9-10]. In addition, the sample without vibration was also fabricated at a pouring temperature of $730^{\circ} \mathrm{C}$ for a comparison.

Table 2: Vibration amplitudes and pouring temperatures used in this study

$\begin{array}{ccc}\text { Round } & \begin{array}{c}\text { Amplitude } \\ (\mathrm{mm})\end{array} & \begin{array}{c}\text { Pouring temperature } \\ \left({ }^{\circ} \mathrm{C}\right)\end{array} \\ & 0.2 & \\ 1 & 0.6 & 730 \\ & 1.0 & \\ & & 690 \\ 2 & 1.0 & 730 \\ & & 770\end{array}$

Metallographic samples were firstly polished, and then etched using the 4\% nital solution. A Me F-3 metallographic microscope and a Quanta 400 scanning electron microscope (SEM) were used to observe the microstructures of the samples. An energy dispersive spectrophotometric (EDS) analysis method attached with the SEM was used to investigate chemical compositions. Quantitative analyses of the microstructures were carried out by Image Tool metallographic analysis software. The grain size $(D)$ and shape factor $(F)$ of the $\alpha-\mathrm{Mg}$ primary phase were calculated based on the following equations ${ }^{[11,12]}$ :

$$
\begin{aligned}
& D=2 \sqrt{\frac{A}{\pi}} \\
& F=\frac{4 \pi A}{P^{2}}
\end{aligned}
$$

where $A$ is the average area of the grains, and $P$ is average perimeter of the grains. When $F$ value varies from 0 to 1 , it means that the grain shape is gradually closer to a circle.

Archimedes' method was used to measure the density of the samples. A ZwickZ100 universal testing machine was used to perform tensile tests with a crosshead speed of $0.5 \mathrm{~mm} \cdot \mathrm{min}^{-1}$. The shape and dimensions of tensile specimens is depicted in Fig. 2.

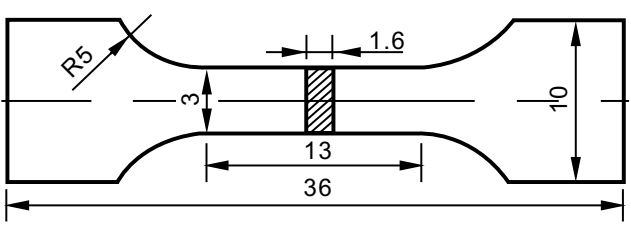

Fig. 2: Shape and dimensions of tensile specimens (unit: $\mathrm{mm}$ ) 


\section{Results}

\subsection{Microstructure and mechanical properties of AZ91D magnesium alloy without vibration}

Figure 3 shows the microstructure of the AZ91D magnesium alloy poured at $730^{\circ} \mathrm{C}$ by EPSC process without vibration. Coarse dendrites of $\alpha-\mathrm{Mg}$ primary phase are observed, and the primary $\alpha-\mathrm{Mg}$ grains show a non-uniform distribution. The average grain size of the $\alpha-\mathrm{Mg}$ primary phase reaches approximately $339.9 \mu \mathrm{m}$, and the shape factor is only 0.42 .

Figure 4 shows SEM microstructure and EDS analysis results of the AZ91D alloy by EPSC process without vibration. It is

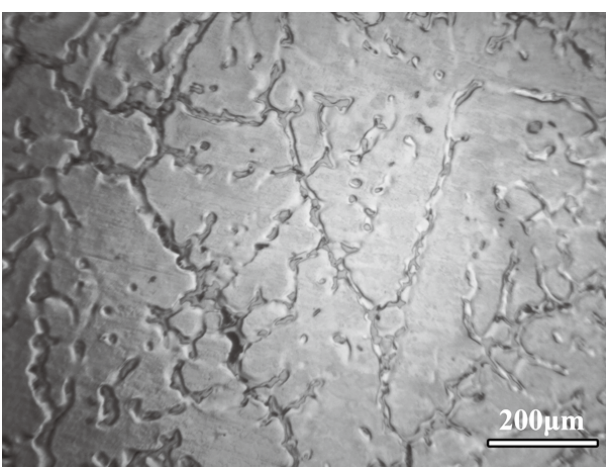

Fig. 3: Microstructure of AZ91D magnesium alloy by EPSC process without vibration
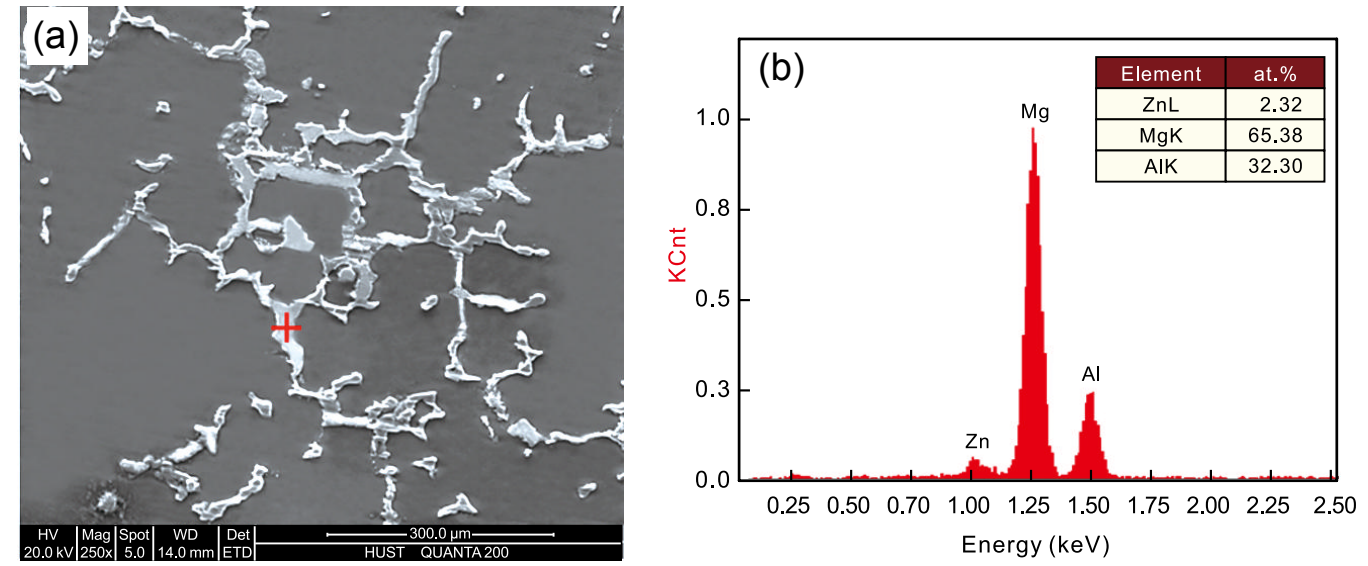

Fig. 4: SEM microstructure (a) and EDS analysis (b) of AZ91D magnesium alloy by EPSC process without vibration

clear that the $\beta-\mathrm{Mg}_{17} \mathrm{Al}_{12}$ phase exhibits a coarse continuous network structure with a non-uniform distribution along the $\alpha-\mathrm{Mg}$ grain boundary, as shown in Fig. 4(a). According to the quantitative metallography assessment, the aspect ratio of the $\beta-\mathrm{Mg}_{17} \mathrm{Al}_{12}$ particles is up to 8.52 . The coarse microstructure of the AZ91D alloy without vibration is mainly due to the adoption of the dry loose-sand during the EPSC process, which results in the slow cooling rate of the liquid metal.

In addition, the shrinkage porosity defects are observed from the SEM fractograph of the tensile sample without vibration, and the intact dendrites are clearly visible, as shown in Fig. 5. In this

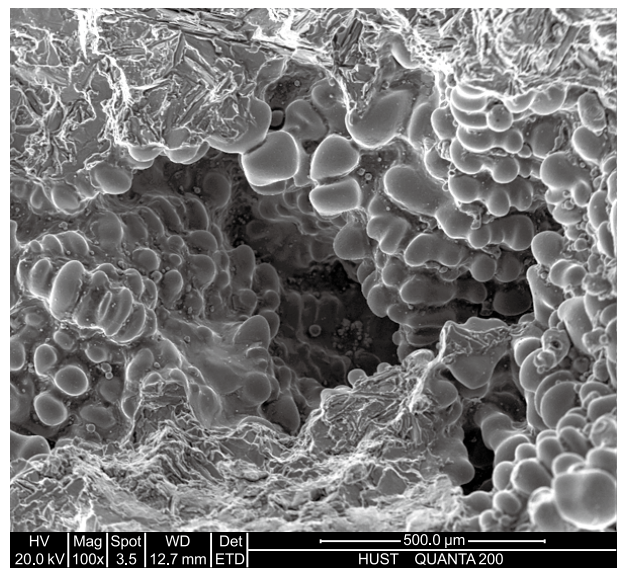

Fig. 5: Shrinkage porosity defects of AZ91D alloy tensile sample without vibration case, the fracture path will preferentially pass by the porosity defects, greatly weakening the mechanical properties of the AZ91D alloy.

According to Figs. 3, 4 and 5, it can be concluded that the microstructure of the AZ91D alloy by the EPSC process without vibration shows a coarse, non-uniform and non-dense characterization, leading to poor mechanical properties. Its ultimate tensile strength and yield strength are 89.1 MPa and 87.5 $\mathrm{MPa}$, respectively.

\subsection{Effect of amplitude on microstructure and tensile properties of AZ91D magnesium alloy}

Figure 6 shows the microstructures of the AZ91D magnesium alloys pouring at $730{ }^{\circ} \mathrm{C}$ under different vibration amplitudes. It is found that some coarse dendrites are still observed when the amplitude is $0.2 \mathrm{~mm}$, as shown in Fig. 6(a). With increasing the amplitude, the microstructure of the AZ91D alloy is continuously refined, and the number of equiaxed grains gradually increase. With an amplitude of $1.0 \mathrm{~mm}$, the microstructure mainly consists of fine equiaxed grains, which are uniformly distributed, as shown in Fig. 6(c), and the dendrites disappear. The quantitative metallography assessments of the microstructural features of the primary $\alpha-\mathrm{Mg}$ phase for different amplitudes are presented in Fig. 7. It is evident that the grain size continuously decreases, and the shape factor gradually increases with the increasing amplitude. SEM microstructures of the AZ91D magnesium alloys 

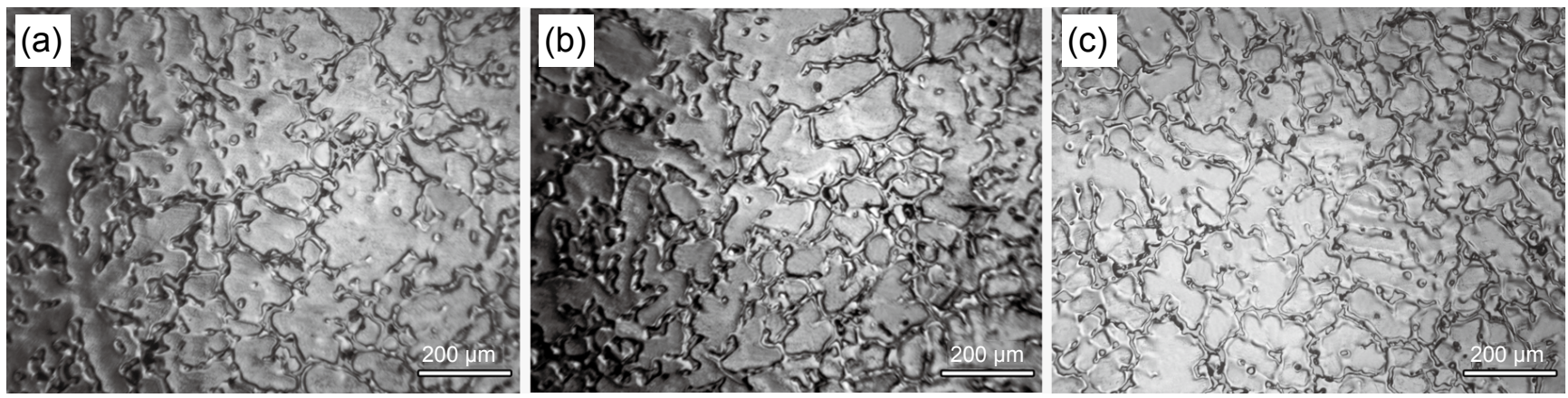

Fig. 6: Microstructures of AZ91D magnesium alloys pouring at $730{ }^{\circ} \mathrm{C}$ under different amplitudes: (a) $0.2 \mathrm{~mm}$;

(b) $0.6 \mathrm{~mm}$; (c) $1.0 \mathrm{~mm}$

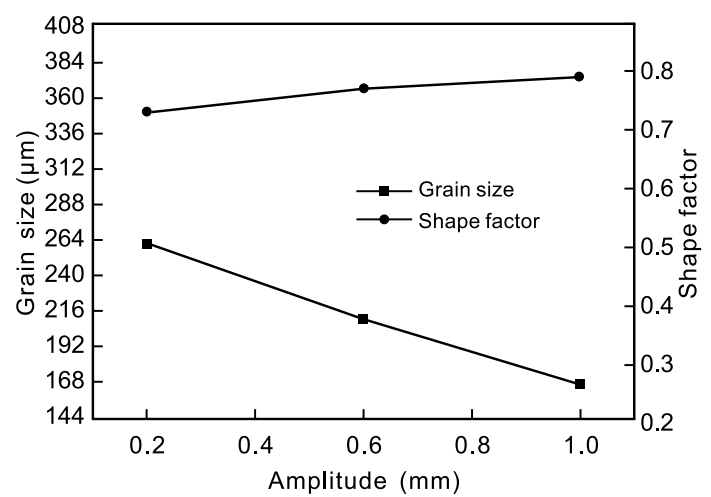

Fig. 7: Effect of amplitude on grain size and shape factor of primary $\alpha-M g$ phase under different amplitudes are shown in Fig. 8. When the amplitude increases, the coarse plate-like $\beta-\mathrm{Mg}_{17} \mathrm{Al}_{12}$ particles significantly decrease, and the short rod and granular $\beta-\mathrm{Mg}_{17} \mathrm{Al}_{12}$ particles obviously increase, which are dispersed uniformly in the microstructure, as shown in Fig. 8(c). As a consequence, the $\beta-\mathrm{Mg}_{17} \mathrm{Al}_{12}$ particles transform from a coarse continuous network structure into a discontinuous granular structure with an increase in amplitude.

The quantitative metallography analyses of the $\beta-\mathrm{Mg}_{17} \mathrm{Al}_{12}$ particles under different amplitudes are shown in Fig. 9. It is clear that the average length, width and aspect ratio of the $\beta-\mathrm{Mg}_{17} \mathrm{Al}_{12}$ particles decrease with increasing amplitude. Consequently, the morphology and size of the $\beta-\mathrm{Mg}_{17} \mathrm{Al}_{12}$
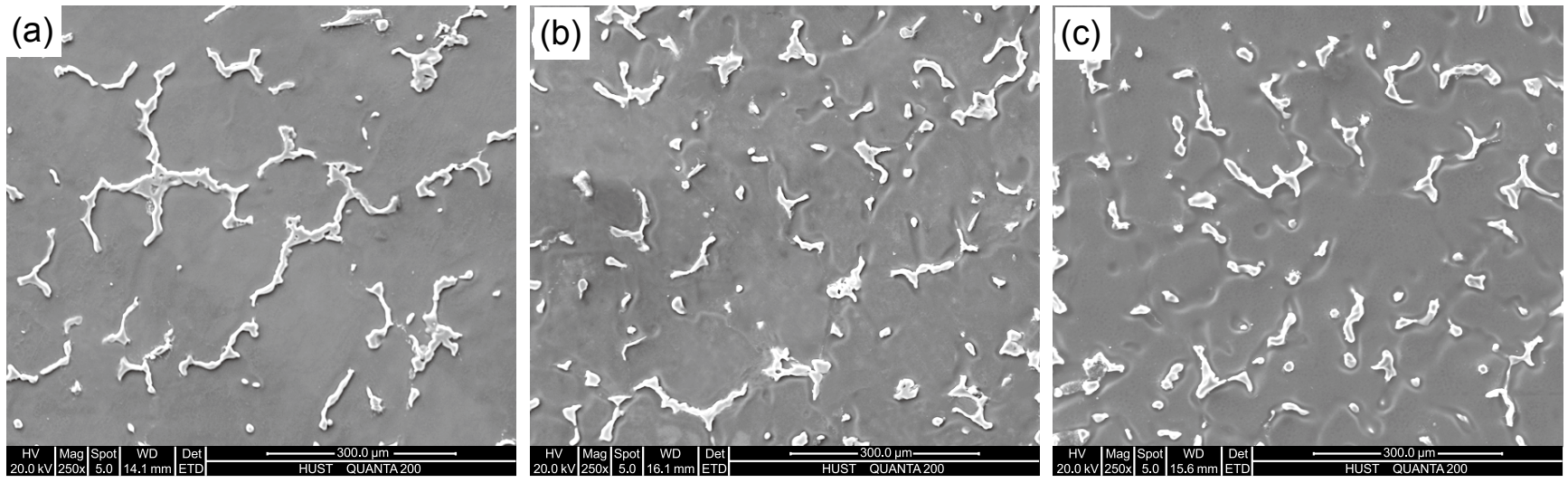

Fig. 8: SEM microstructures of AZ91D magnesium alloys using different amplitudes: (a) $0.2 \mathrm{~mm}$; (b) $0.6 \mathrm{~mm}$; (c) $1.0 \mathrm{~mm}$
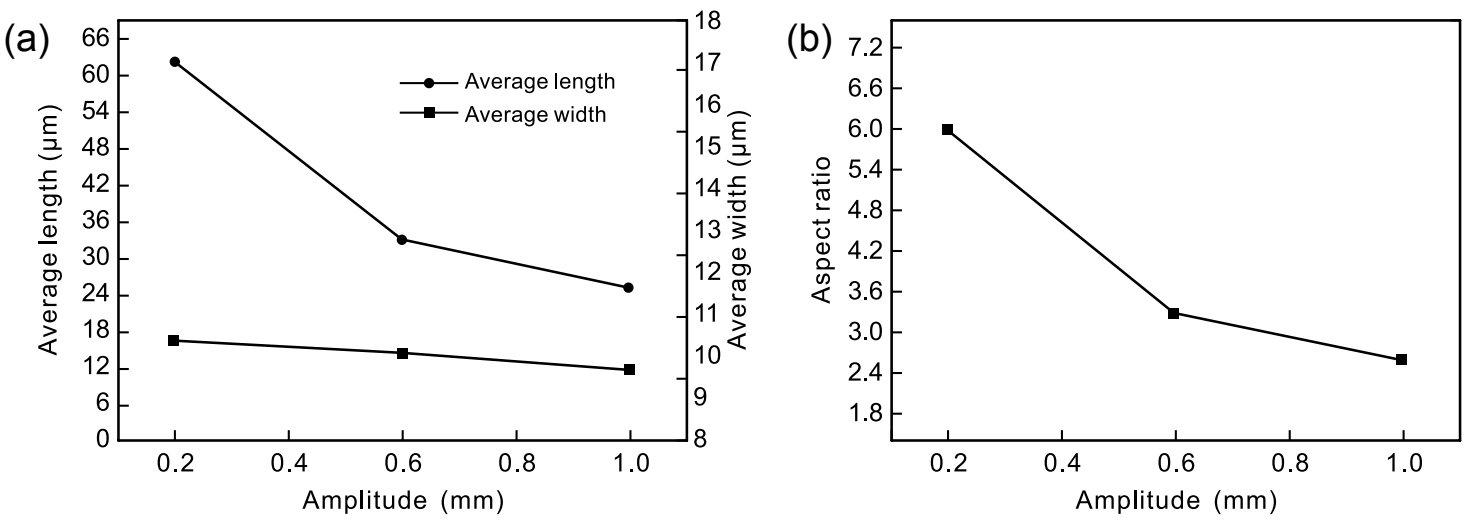

Fig. 9: Effect of amplitude on $\beta-M_{17} A I_{12}$ particles: (a) average length and width; (b) aspect ratio 
phase are greatly improved with the increase of the amplitude (Fig. 8).

Figures 10 and 11 show the effect of the amplitude on density and tensile properties of the AZ91D alloy, respectively. It is found that the density, ultimate tensile strength as well as the yield strength of the AZ91D alloy obviously increase with an increase in amplitude. It suggests that the amplitude has a significant effect on the tensile properties of the AZ91D alloy during the EPSC process associated with mechanical vibration. With a vibration amplitude of $1.0 \mathrm{~mm}$, the tensile strength and yield strength of the AZ91D alloy are increased by $60 \%$ and $38 \%$, respectively, compared to the alloy without vibration.

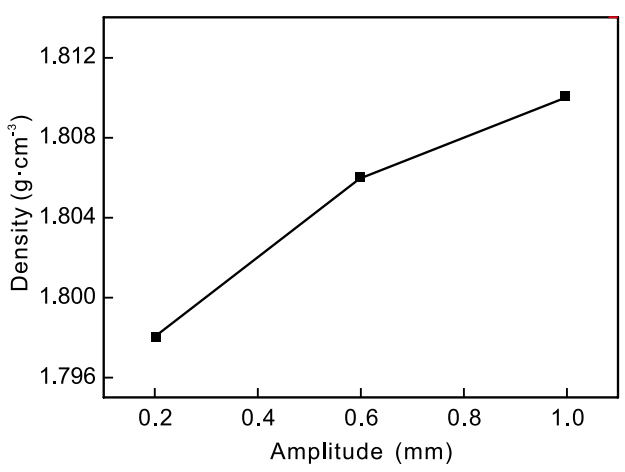

Fig. 10: Effect of amplitude on density of AZ91D magnesium alloy

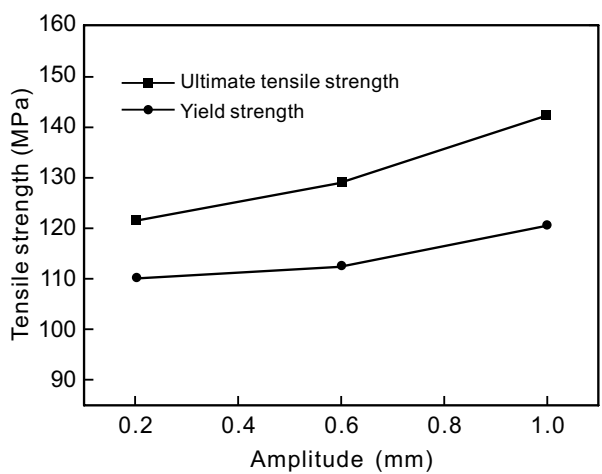

Fig. 11: Effect of amplitude on tensile strength of AZ91D magnesium alloy

\subsection{Effect of pouring temperature on microstructure and mechanical properties of AZ91D magnesium alloy}

Microstructures of the AZ91D magnesium alloys at different pouring temperatures and $1.0 \mathrm{~mm}$ amplitude are displayed in Fig. 12. In the microstructure of the AZ91D alloy with a pouring temperature of $690^{\circ} \mathrm{C}$, the primary $\alpha-\mathrm{Mg}$ grains are very fine. However, some fine dendrites are observed which show nonuniform distributions, as shown in Fig. 12(a). With the increase of pouring temperature to $730{ }^{\circ} \mathrm{C}$, the dendrites disappear, and the microstructure mainly consists of fine equiaxed grains with a uniform distribution, as shown in Fig. 12(b). Further increasing pouring temperature up to $770{ }^{\circ} \mathrm{C}$, the primary $\alpha-\mathrm{Mg}$ phase shows a serious coarsening, as shown in Fig. 12(c).
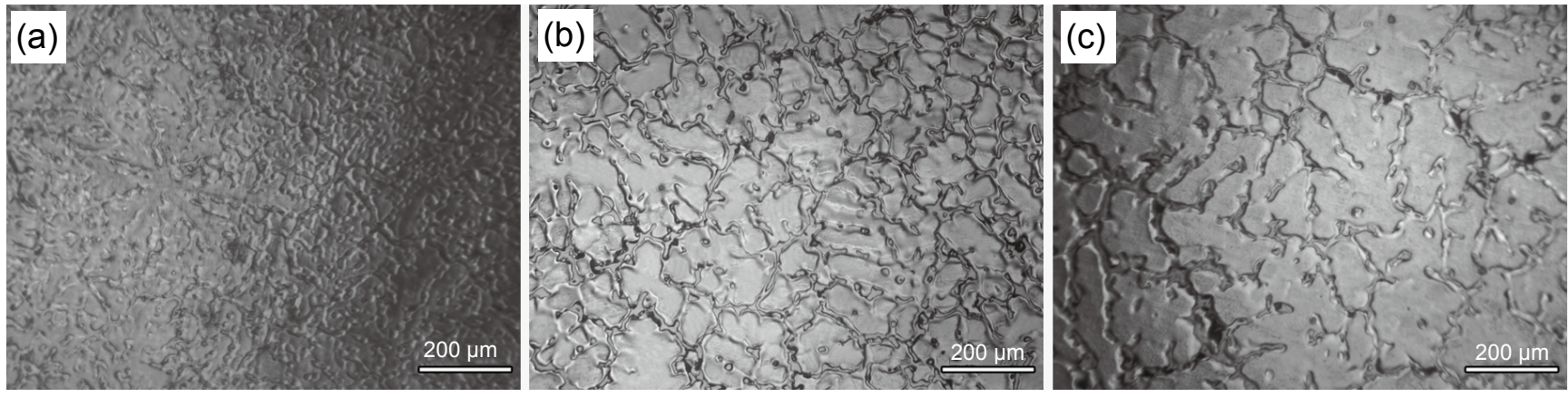

Fig. 12: Microstructures of AZ91D magnesium alloys pouring at different pouring temperatures and $1.0 \mathrm{~mm}$ amplitude: (a) $690^{\circ} \mathrm{C}$; (b) $730^{\circ} \mathrm{C}$; (c) $770^{\circ} \mathrm{C}$

The quantitative metallography analyses of the $\alpha-\mathrm{Mg}$ primary phase for different pouring temperatures are shown in Fig. 13. With the increase of pouring temperature from $690{ }^{\circ} \mathrm{C}$ to $730{ }^{\circ} \mathrm{C}$, the grain size shows a slight increase, while the shape factor displays an obvious increase. Further increasing pouring temperature to $770{ }^{\circ} \mathrm{C}$, the grain size sharply increases, and the shape factor obviously decreases.

SEM microstructures of the AZ91D magnesium alloys at different pouring temperatures are shown in Fig. 14. When the pouring temperature is $690{ }^{\circ} \mathrm{C}$, the $\beta-\mathrm{Mg}_{17} \mathrm{Al}_{12}$ particles show a short rod and granular morphology, as shown in Fig. 14(a). Increasing the pouring temperature to $730{ }^{\circ} \mathrm{C}$, the $\beta-\mathrm{Mg}_{17} \mathrm{Al}_{12}$ particles are also very fine. When the pouring temperature further increases to $770{ }^{\circ} \mathrm{C}$, the $\beta-\mathrm{Mg}_{17} \mathrm{Al}_{12}$ particles display an obvious coarsening, as shown in Fig. 14(c). Figure 15 shows

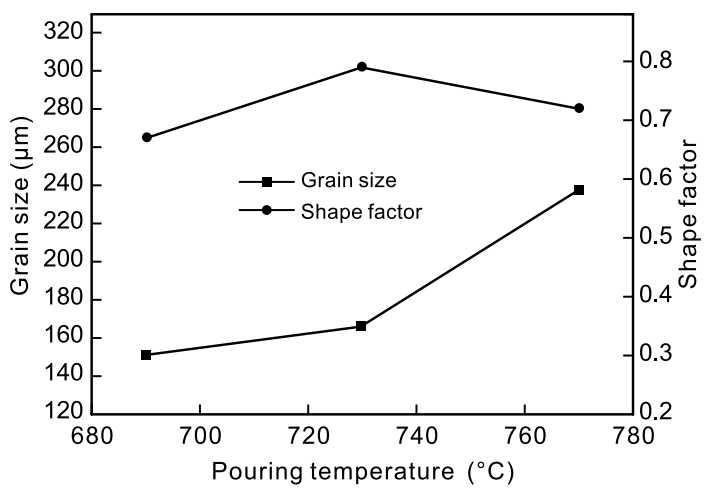

Fig. 13: Effects of pouring temperature on grain size and shape factor of primary $\alpha-M g$ phase 

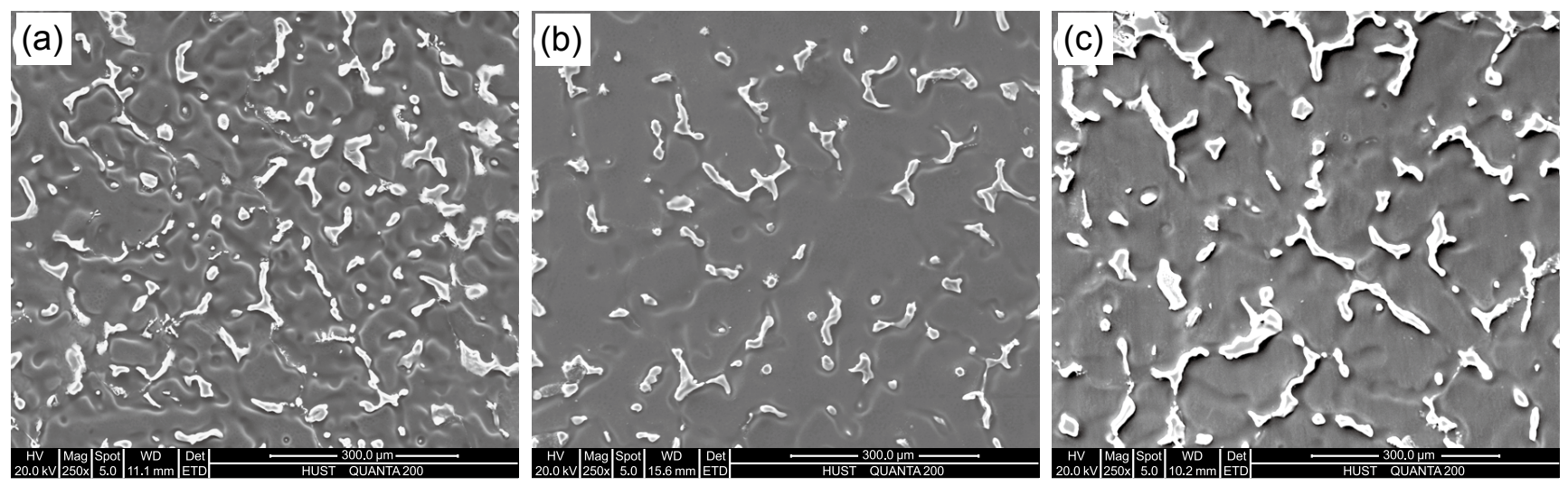

Fig. 14: SEM microstructures of AZ91D magnesium alloys using different pouring temperatures: (a) $690^{\circ} \mathrm{C}$; (b) $730^{\circ} \mathrm{C}$; (c) $770^{\circ} \mathrm{C}$
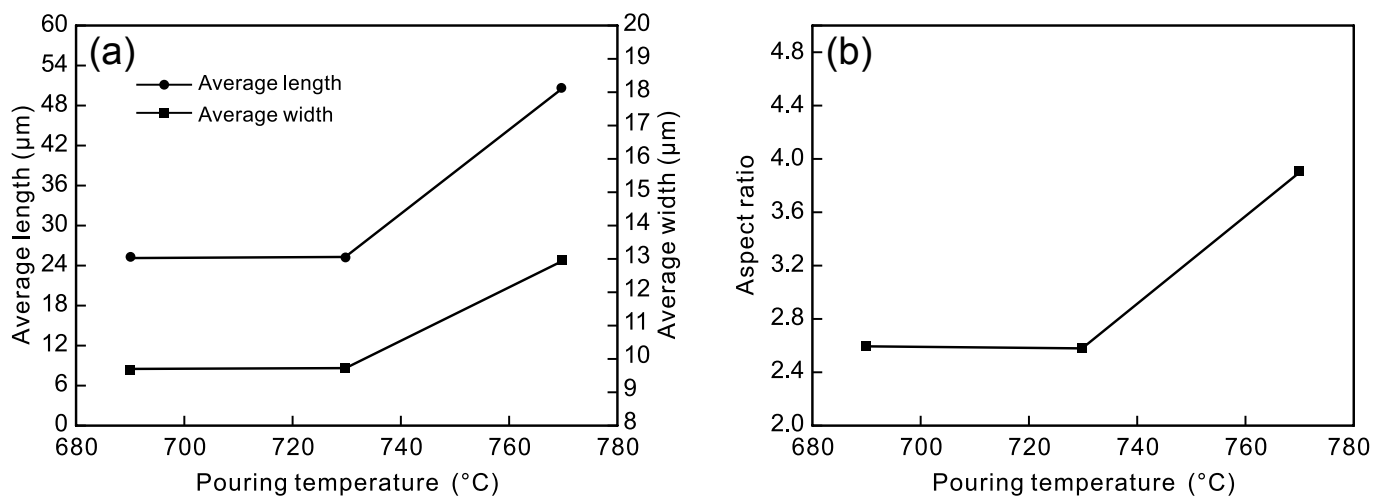

Fig. 15: Effect of pouring temperature on $\beta-\mathrm{Mg}_{17} \mathrm{Al} \mathrm{l}_{12}$ particles: (a) average length and width; (b) aspect ratio

the quantitative analyses of the $\beta-\mathrm{Mg}_{17} \mathrm{Al}_{12}$ particles at different pouring temperatures. It is clear that the average length, width, and aspect ratio of the $\beta-\mathrm{Mg}_{17} \mathrm{Al}_{12}$ particles at a pouring temperature of $770{ }^{\circ} \mathrm{C}$ show a significant increase compared to those of the samples at pouring temperatures of $690^{\circ} \mathrm{C}$ and $730^{\circ} \mathrm{C}$.

Effects of pouring temperature on density and tensile properties of the AZ91D magnesium alloy are shown in Fig. 16 and Fig. 17, respectively. As can be seen, the density, ultimate tensile strength and yield strength of the AZ91D alloy continuously decrease with increasing the pouring temperature, particularly at $770{ }^{\circ} \mathrm{C}$. It should be pointed out that an excessive pouring temperature significantly decreases the tensile properties of the AZ91D alloy by the EPSC process associated with $1.0 \mathrm{~mm}$ amplitude of mechanical vibration.

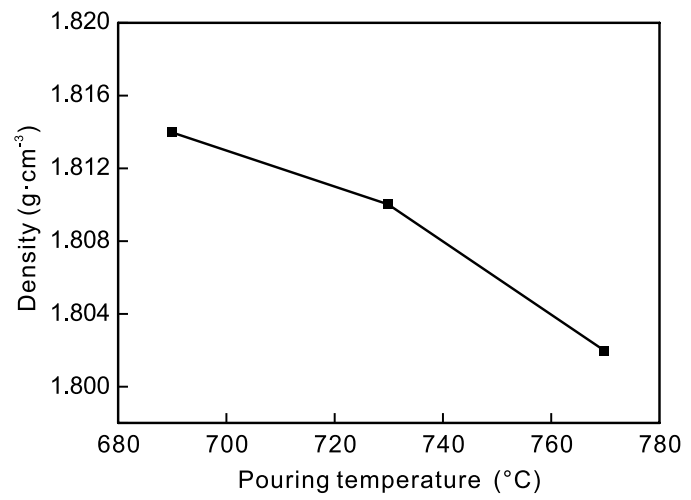

Fig. 16: Effect of pouring temperature on density of AZ91D magnesium alloy

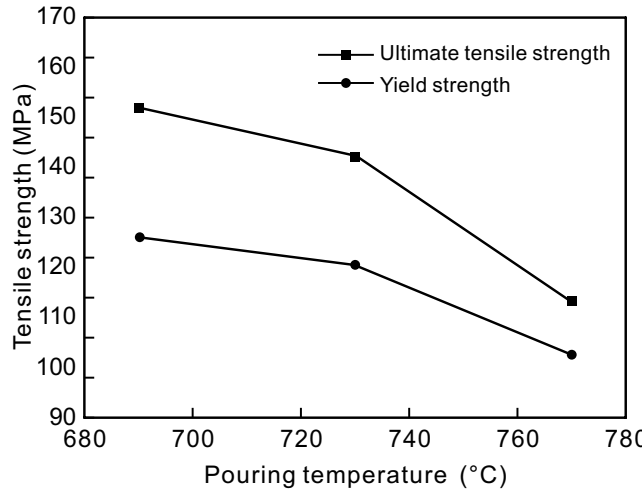

Fig. 17: Effect of pouring temperature on tensile strength of AZ91D magnesium alloy

\section{Discussion}

In general, the microstructure of the alloy mainly depends on the nucleation stage and subsequent growth condition, and the refinement of the microstructure is attributed to the sufficient nuclei in the melt. Without the vibration condition, the cooling rate of the molten metal is slow because of the adoption of the dry loose-sand, which increases the solidification time of the liquid metal. As a consequence, no sufficient nuclei are generated in the melt during the solidification process, leading to the formation of coarse dendritic microstructure.

When the mechanical vibration is applied in the EPSC process, the microstructure is significantly improved, which 
can be explained by the following reasons. First, when the liquid metal contacts with the cold wall of the ceramic shell mold, the liquid metal quickly solidifies, forming initial solidified fine dendrites. These fine dendrites are easily broken off by the vibrating forces ${ }^{[8]}$. Moreover, the mechanical vibration induces a forced convection in the liquid metal, which enhances the fragmentations of the dendrites in the liquid metal ${ }^{[13-15]}$. The detached dendrite arms are then carried into other positions of the liquid metal, acting as new nuclei. When the dendrite arms are gradually detached, the nucleation rate greatly increases, thereby resulting in a significant refinement of the microstructure. Second, the vibration brings a high heat transfer from inside the liquid metal to the ceramic mold interface because of the alternated movement of the liquid metal, forming a high solidification rate of the liquid metal ${ }^{[16,17]}$. It will give rise to a greater undercooling, and stimulate more existing nuclei in the liquid metal to start a spontaneous heterogeneous solidification. Therefore, the microstructure is clearly refined. What is more, the temperature and solute distribution in all directions of the liquid metal are much more uniform, resulting from the vigorous convection and rotation of grains ${ }^{[18-20]}$, and the growth of the dendrites will be restrained, promoting the formation of the fine equiaxed grains.

By increasing amplitude, the forced convection in the liquid metal is greatly increased ${ }^{[21-23]}$. In this case, the dendrite arms are easily broken, obviously increasing the number of the nuclei in the liquid metal. Meanwhile, the greater amplitude also enhances the heat transfer process of the liquid metal. Consequently, the refinement degree of the microstructure significantly increases with increasing amplitude, as shown in Fig. 7. With respect to pouring temperature, a greater undercooling is obtained as the pouring temperature is low, resulting in a fine dendrite structure. However, the solidification time of the liquid metal is short, thereby decreasing the action time of the mechanical vibration on the liquid metal. As a consequence, some fine dendrites are still detected, as shown in Fig. 12(a). In contrast, a too high pouring temperature promotes the coarsening of the microstructure, as shown in Fig. 12(c). In this case, the mechanical vibration also cannot play a good role in the grain refinement. In light of Hall-Petch relationship ${ }^{[24]}$, the finer grain size will remarkably increase the strength of the alloys.

The mechanical vibration obviously increases the density of the AZ91D alloy, which can be explained by the fact that the mechanical vibration promotes the filling ability and feeding capacity of the liquid metal ${ }^{[5,13,25]}$, and thereby improves the densification of the castings. With increasing the amplitude, the filling ability and feeding capacity of the liquid metal is further enhanced, and the density of the AZ91D alloy is continuously increased, as shown in Fig. 10. Increasing pouring temperature may give rise to the combustion, inspiration, and oxidation of the AZ91D alloy melt, leading to the decrease of the density, as shown in Fig. 16. However, too low a pouring temperature may generate misrun and cold shut defects.

The experimental results indicate that the mechanical vibration remarkably improves the microstructure and densification of the AZ91D alloy. By increasing amplitude or decreasing pouring temperature, both the microstructure and densification of the AZ91D alloy are improved, thereby increasing the tensile properties.

\section{Conclusions}

The effect of vibration amplitude and pouring temperature on the microstructure and tensile properties of the AZ91D alloy by the EPSC process associated with mechanical vibration was studied. The conclusions are obtained as follows:

(1) The microstructure of the AZ91D alloy by the EPSC process without vibration shows a coarse, non-uniform and nondense characterization, leading to poor mechanical properties. After the mechanical vibration is applied, the fine equiaxed grains and discontinuous granular structure of the $\beta-\mathrm{Mg}_{17} \mathrm{Al}_{12}$ phase are obtained, and the densification of the AZ91D alloy increases, resulting in a significant improvement of the tensile properties of the AZ91D alloy. The tensile strength and yield strength of the AZ91D alloy with a vibration amplitude of 1.0 $\mathrm{mm}$ and a pouring temperature of $730^{\circ} \mathrm{C}$ increased by $60 \%$ and $38 \%$, respectively, compared to the alloy without vibration.

(2) When pouring at $730{ }^{\circ} \mathrm{C}$, with the increase of the amplitude, the grain size continuously decreases, the shape factor gradually increases, and the $\beta-\mathrm{Mg}_{17} \mathrm{Al}_{12}$ particles are obviously refined, which lead to an increase in the tensile properties of the AZ91D alloy.

(3) At a vibration amplitude of $1.0 \mathrm{~mm}$, with the increase of pouring temperature, the microstructures are gradually coarsened, resulting in a continuous decrease of the tensile properties of the AZ91D alloy. A reasonable pouring temperature is $730{ }^{\circ} \mathrm{C}$ during the EPSC process associated with mechanical vibration in this study.

\section{Acknowledgement}

The authors gratefully acknowledge the financial support from the State Key Laboratory of Materials Processing and Die \& Mould Technology, Huazhong University of Science and Technology (P2020-05).

\section{References}

[1] Jiang Z L, Fan Z T, Jiang W M, et al. Interfacial microstructures and mechanical properties of $\mathrm{Mg} / \mathrm{Al}$ bimetal produced by a novel liquid-liquid compound casting process. Journal of Materials Processing Technology, 2018, 261: 149-158.

[2] Bonnah R C, Fu Y, Hao H. Microstructure and mechanical properties of AZ91 magnesium alloy with minor additions of Sm, Si and Ca elements. China Foundry, 2019, 16(5): 319-325.

[3] Jiang W M, Li G Y, Fan Z T, et al. Investigation on the interface characteristics of $\mathrm{Al} / \mathrm{Mg}$ bimetallic castings processed by lost foam casting. Metallurgical and Materials Transactions A, 2016, 47(5): 2462-2470.

[4] Jiang W M, Fan Z T, Liu D J, et al. Influence of process parameters on filling ability of A356 aluminium alloy in expendable pattern shell casting with vacuum and low pressure. International Journal of Cast Metals Research, 2012, 25(1): 47-52. 
[5] Taghavi F, Saghafian H, Kharrazi Y H K. Study on the effect of prolonged mechanical vibration on the grain refinement and density of A356 aluminum alloy. Materials and Design, 2009, 30(5): 1604-1611.

[6] Xiao B T, Fan Z T, Jiang W M, et al. Effect of vibration frequency on primary phase and properties of grey cast iron fabricated by lost foam casting. China Foundry, 2020, 17(1): 1-7.

[7] Chirita G, Stefanescu I, Soares D, et al. Influence of vibration on the solidification behaviour and tensile properties of an Al$18 w t . \% S i$ alloy. Materials and Design, 2009, 30(5): 15751580.

[8] Guo H M, Zhang A S, Yang X J, et al. Microstructure formation and mechanical properties of AZ31 magnesium alloy solidified with a novel mechanical vibration technique. Metallurgical and Materials Transactions A, 2014, 45: 438-446.

[9] Jiang W M, Fan Z T, Chen X, et al. Combined effects of mechanical vibration and wall thickness on microstructure and mechanical properties of A356 aluminum alloy produced by expendable pattern shell casting. Materials Science and Engineering A, 2014, 619: 228-237.

[10] Jiang W M, Chen X, Wang B J, et al. Effects of vibration frequency on microstructure, mechanical properties, and fracture behavior of A356 aluminum alloy obtained by expendable pattern shell casting. International Journal of Advanced Manufacturing Technology, 2016, 83(1-4): 167-175.

[11] Zhu J W, Jiang W H, Li G Y, et al. Microstructure and mechanical properties of SiCnp/Al6082 aluminum matrix composites prepared by squeeze casting combined with stir casting. Journal of Materials Processing Technology, 2020, 283: 116699.

[12] Jiang W M, Fan Z T, Dai Y C, et al. Effects of rare earth elements addition on microstructures, tensile properties and fractography of A357 alloy. Materials Science and Engineering A, 2014, 597: 237-244.

[13] Campbell J. Effects of vibration during solidification. International Materials Reviews, 1981, 2: 71-106.

[14] Wu S S, Xie L Z, Zhao J W, et al. Formation of non-dendritic microstructure of semi-solid aluminum alloy under vibration. Scripta Materialia, 2008, 58(7): 556-559.
[15] Doherty R D. Comments on "Mechanical deformation of dendrites by fluid flow during the solidification of undercooled melts". Scripta Materialia, 2003, 49(12): 1219-1222.

[16] Abu-Dheir N, Khraisheh M, Saito K, et al. Silicon morphology modification in the eutectic Al-Si alloy using mechanical mold vibration. Materials Science and Engineering A, 2005, 393(12): 109-117.

[17] Taghavi F, Saghafian H, Kharrazi Y H K. Study on the ability of mechanical vibration for the production of thixotropic microstructure in A356 aluminum alloy. Materials and Design, 2009, 30(1): 115-121.

[18] Flemings M C. Behavior of metal alloys in the semisolid state. Metallurgical Transactions: A, 1991, 22: 957-981.

[19] Fan Z. Semisolid metal processing. International Materials Reviews, 2002, 47(2): 49-85.

[20] Li T, Lin X, Huang W D. Morphology evolution during solidification under stirring. Acta Materialia, 2006, 54: 48154824.

[21] Fedyushkin A, Bourago N, Polezhaev V, et al. The influence of vibration on hydrodynamics and heat-mass transfer during crystal growth. Journal of Crystal Growth, 2005, 275(1-2): 1557-1563

[22] Lyubimov D V, Lyubimova T P, Tcherepanov A A, et al. Vibration influence on fluid interfaces. Comptes Rendus Mécanique, 2004, 332(5-6): 467-472.

[23] Volfson D, Vinals J. Morphological stability analysis of directional solidification into an oscillatory fluid layer. Physics of Fluids, 2001, 13(12): 3599-3609.

[24] Jiang W M, Fan Z T, Liu D J, et al. Correlation of microstructure with mechanical properties and fracture behavior of A356-T6 aluminum alloy fabricated by expendable pattern shell casting with vacuum and low-pressure, gravity casting and lost foam casting. Materials Science and Engineering A, 2013, 560: 396-403.

[25] Abdul-Karem W, Green N, Al-Raheem K F. Vibration-assisted filling capability in thin wall investment casting. International Journal of Advanced Manufacturing Technology, 2012, 61(912): 873-887. 